\title{
Relationship between Leisure Immersion and Life Satisfaction of Marine Leisure Sports Enthusiasts
}

\author{
Han, Kyung-Seok, Yang, Chun-Ho
}

\begin{abstract}
The purpose of this study was to investigate the relationship between leisure immersion and life satisfaction. The main group considered for this study was marine leisure sports enthusiasts. To conduct this study, a survey in the form of a questionnaire was used. The survey targeted 256 marine leisure sports enthusiasts in 2018. For analysis of the data obtained, SPSS 12.0 statistical program was used. From the use of the software, frequency analysis, exploratory factor analysis, reliability test, correlation analysis, and multiple regression analysis were conducted. This enabled the following findings to be reached. Firstly, results obtained from the study pointed that the leisure lifestyle of marine leisure sports enthusiasts has a positive correlation with leisure immersion and life satisfaction. Secondly, among the leisure lifestyle, family-oriented, rational planning, and work-oriented all had a positive influence on the behavioral immersion, and the sensory pursuit, relationship-oriented, and leisure helplessness all had a positive influence on cognitive immersion. Third, among the leisure lifestyle, family-oriented, relationship-oriented, rational planning, and work-oriented all had a positive influence on the physical activity satisfaction, and family-oriented, sensory pursuit, relationship-oriented, and work-oriented all had a positive influence on rest activity satisfaction, and the family-oriented, rational planning, and leisure helplessness all had a positive influence on social activity satisfaction. In conclusion, it was observed that the leisure lifestyle of marine leisure sports enthusiasts has a positive correlation with leisure immersion and life satisfaction. It was also observed that the leisure lifestyle has a partial influence on leisure immersion, behavioral immersion and cognitive immersion affecting the leisure lifestyle were incompatible with each other. In addition, the leisure lifestyles had a partial impact on life satisfaction, where among them, the leisure lifestyle of family-oriented, relationship-oriented, and work-oriented all had an influence on the life satisfaction.
\end{abstract}

Keywords : Marine, Characteristics, Leisure, Lifestyle Satisfaction.

\section{INTRODUCTION}

People have very different lifestyles even in cases where they are from the same culture and social class. A lifestyle can be defined as a characteristic life form that distinguishes itself from others, which are common to all members of

Revised Manuscript Received on July 22, 2019.

Han, Kyung-Seok, Hanseo University, Dept. of Marine Sports, Seosan,31962, Korea

Yang, Chun-Ho, Hanseo University, Dept. of Marine Sports, Seosan,31962, Korea society or the entire society, where people organize personal relationships and use resources to engage with social and natural environments [1]. Therefore, lifestyle refers to the way individuals live in this world. Lifestyle can thus be described by what individual does, what their interest are, opinions that they have on various issues among others [2]. Since a typical lifestyle is referred to as the pattern of lifestyle or the values of individuals [3], leisure lifestyle refers to a characteristic leisure lifestyle distinct from others and refers to unique leisure activity area, leisure areas of interest, leisure attitudes and values, among others [4]. In other words, instead of simply separating the types of leisure through certain criteria, it can be seen as a characteristic leisure type considering the personality, psychological characteristics, and life pattern, etc. that affects leisure participation [5].

In the current society, many individuals engage in various leisure activities. This is because most people in the society have solved the problems of survival and livelihood which were the main challenges facing past civilizations. This has thus allowed for the current society to focus on how to live a pleasant and meaningful life [6]. It is worth noting that this form of living is also applicable in our country. This can be seen in various scenarios such as the system of working 5 days a week, shortening of working hours, explosive growth of the leisure market, and the increase in the leisure cost of individual citizens. The growth of the leisure industry in the country is supported with factors such as the growth of national income, due to the geographical conditions of having abundant marine resources by being a peninsula, the types of leisure utilizing marine leisure sports are developing rapidly.

Despite this economic growth and the breakthrough in leisure, studies on the variables related to leisure lifestyle and leisure targeting the country's marine leisure sports participants are insufficient. Especially, despite the fact that the leisure lifestyle associated with leisure can have overall access to individual leisure, studies have not been actively conducted yet. One of the variables closely related to leisure life style is leisure immersion. Leisure immersion can be described as the peak experience or optimal experience in leisure. These experiences are especially common in leisure [7]. For leisure immersion, freedom from bondage, voluntary choice of desired activities, pleasure of participating in 
activities, and the leisure activities should be culturally recognized [8].

Therefore, the leisure immersion occurs when the human skill level is in harmonious balance with the difficulty of the given environment. This can be seen from previous studies on lifestyle and leisure immersion.

In a study targeting the ski participants, it was found that each lifestyle had a significant effect on the immersion experience [9], and the lifestyle of college students had a statistically significant effect on leisure immersion according to the participation of leisure activities [10]. Furthermore, previous studies have reported that lifestyle and leisure immersion are variables closely related to life satisfaction as well as the relationship between each other [11], [12]. The reason why leisure life style attracts attention as important sociological variables along with life satisfaction is because it has been recognized as an important determinant of leisure activities. In other words, life satisfaction is an assessment of their own happiness, and because it means the harmonious satisfaction of aspiration and purpose of personal life on happiness.

As three sides of Korea are surrounded by the sea, and due to the nature-friendly relationship with the sea, the marine leisure sports activities have become a big part of life. Therefore, identifying the leisure lifestyle of marine leisure sports participants seems to fulfill its role as a basic data for vitalizing the marine leisure sports and proceeding in a desirable direction. Therefore, the purpose of this study is to identify the relationship between leisure immersion and life satisfaction according to the leisure lifestyle of marine leisure sports participants. To achieve this goal, the following research objectives were set. First, to investigate the correlation between leisure lifestyles, leisure immersion and life satisfaction of marine leisure sports participants. Secondly, to investigate leisure lifestyle of marine leisure sports participants and relate it to leisure immersion. Third, to investigate the relationship between leisure lifestyle of marine leisure sports enthusiasts to life satisfaction.

\section{STUDY METHODS}

\subsection{Study subjects}

To conduct this study, 300 marine leisure sports enthusiast were sampled using cluster random sampling. Consent was obtained from the identified study subjects before the survey and a questionnaire was distributed to the selected subjects. The questionnaire was created using self-assessment method. The completed questionnaires were collected immediately at the site. Among the completed questionnaires, questionnaires having missing or insincere responses were excluded. This led to 256 questionnaires being clarified and used as data for final analysis.

\subsection{Survey tool}

In this study, questionnaires were used as survey tools. The questionnaire was composed of 4 questions on general characteristics of the subjects, 28 questions on leisure lifestyle as an independent variable, 8 questions on leisure immersion as a dependent variable, and 17 questions on life satisfaction. The measurement method for each question used the Likert scale of 'absolutely not at all, 1 point', 'not at all, 2 points', 'normal, 3 points', 'agree, 4 points' and 'very agree, 5 points.'

\subsection{Leisure lifestyle}

For the survey tool for measuring leisure lifestyle, the leisure lifestyle scale developed by Woo \& Sohn (13) and partially modified by Sohn, Oh, \& Woo (14), Joo \& Kim (5), Lee \& Kim (15) was modified and supplemented to fit this study. The sub-variables of leisure life style were classified into 6 factors; family-oriented, sensory pursuit, relationship-oriented, rational planning, work-oriented, and leisure helplessness.

\subsection{Leisure immersion}

For the survey tool for measuring leisure immersion, the leisure immersion scale developed by Scanlan, et. al. (16) which was partially modified by An \& Hwang (17), Yoon (18), Kim, Lee \& Jeon (19) was modified and supplemented to fit this study. The sub-variables of leisure immersion were classified into 2 factors; cognitive immersion and behavioral immersion.

\subsection{Leisure satisfaction}

For the survey tool for measuring life satisfaction, the life satisfaction scale developed by Raghed \& Beard (20) which was partially modified by Ha (21), Jang, et. al. (22), Moon (23) was modified and supplemented to fit this study. The sub-variables of life satisfaction were classified into 3 factors; satisfaction with physical activity, satisfaction with rest activity, and satisfaction with social activity.

\subsection{Validity and reliability}

In order to test the validity and reliability of the questionnaire in this study, exploratory factor analysis and Cronbach's awere conducted. The factor rotation was performed through an orthogonal rotation method of Varimax rotation. In addition, verification of KMO and Bartlett's sphere formation was also performed simultaneously.

\subsection{Leisure Lifestyle}

For leisure lifestyle, the Bartlett unit matrix was 3444.260, the probability of significance was .001, and the KMO index was .903 showing the selection of the variables was appropriate. Based on this, 6 factors were extracted as a result conducting factor analysis on 28 questions, and it was shown to explain approximately $68.417 \%$ of total variance. The eigenvalues for the sub-factors of the leisure lifestyle were family-oriented(.708 .783), sensory pursuit(.530 .803), relationship-oriented (.511 .802), rational planning (.441 .731), work-oriented(.498 .835), and leisure helplessness (.498 .835). In addition, the reliability value has shown a 
relatively high level of reliability with family-oriented (.935), sensory pursuit(.935), relationship-oriented (.936), rational planning(.937), work-oriented (.935), and leisure helplessness(.937).

\subsection{Leisure Immersion}

For leisure immersion, the Bartlett unit matrix was 563.710 , the probability of significance was .001 , and the KMO index was .831 showing the selection of the variables was appropriate. Based on this, 2 factors were extracted as a result conducting factor analysis on 8 questions, and it was shown to explain approximately $62.963 \%$ of total variance.

The eigenvalues for the sub-factors of the leisure immersion were shown as behavioral immersion(.765 .836) and cognitive immersion(.610 .777). In addition, the reliability value has shown a relatively high level of reliability with behavioral immersion(.935) and cognitive immersion(.933).

\subsection{Life Satisfaction}

For life satisfaction, the Bartlett unit matrix was 1738.706, the probability of significance was .001 , and the KMO index was .930 showing the selection of the variables was appropriate. Based on this, 3 factors were extracted as a result conducting factor analysis on 17 questions, and it was shown to explain approximately $62.597 \%$ of total variance. The eigenvalues for the sub-factors of the life satisfaction were shown as physical activity satisfaction(.564 .773), rest activity satisfaction(.585 .744), and social activity satisfaction(.713 .779). In addition, the reliability value have shown a relatively high level of reliability with physical activity satisfaction(.931), rest activity satisfaction(.931), and social activity satisfaction(.938).

\subsection{Data processing}

The data collected for the purpose of the study was total of 191 copies excluding the questionnaires which were deemed inappropriate for the study.

To confirm the normal distribution, validity and reliability of the collected data, statistical analysis, exploratory factor analysis and reliability analysis were conducted using SPSS 21.0. Correlation analysis was conducted in order to establish the relationship between variables. Multiple regression analysis was conducted in order to investigate the causal relationship between variables. The level of significance was $\alpha=.05$.

\section{RESEARCH RESULTS}

\subsection{Correlation analysis result}

Correlation analysis was conducted in order to investigate the relationship between leisure immersion and life satisfaction for leisure lifestyle of marine leisure sports enthusiasts. The results showed that family-oriented had a positive correlation with behavioral immersion $(r=.857)$ and cognitive immersion( $\mathrm{r}=.460)$. The sensory pursuit had a positive correlation with behavioral immersion $(\mathrm{r}=.519)$ and cognitive immersion( $r=.852$ ). The relationship-oriented had a positive correlation with behavioral immersion $(r=.501)$ and cognitive immersion $(r=.685)$. The rational planning had a positive correlation with behavioral immersion $(\mathrm{r}=.618)$ and cognitive immersion $(\mathrm{r}=.532)$. The work-oriented had a positive correlation with behavioral immersion $(r=.674)$ and cognitive immersion( $r=.638)$. The leisure helplessness had a positive correlation with behavioral immersion $(r=.532)$ and cognitive immersion( $\mathrm{r}=.610)$. In addition, the family-oriented had a positive correlation with physical activity satisfaction( $\mathrm{r}=.789), \quad$ rest activity satisfaction $(r=.651)$, and social activity satisfaction $(r=.593)$. The sensory pursuit had a positive correlation with physical activity satisfaction( $\mathrm{r}=.559), \quad$ rest activity satisfaction $(\mathrm{r}=.659)$, and social activity satisfaction $(\mathrm{r}=.449)$. The relationship-oriented had a positive correlation with physical activity satisfaction( $\mathrm{r}=.612)$, rest activity satisfaction $(r=.757)$, and social activity satisfaction $(r=.444)$. The rational planning had a positive correlation with physical activity satisfaction( $\mathrm{r}=.645)$, rest activity satisfaction $(\mathrm{r}=.579)$, and social activity satisfaction $(\mathrm{r}=.542)$. The work-oriented had a positive correlation with physical activity satisfaction( $\mathrm{r}=.656), \quad$ rest activity satisfaction( $\mathrm{r}=.696)$, and social activity satisfaction( $\mathrm{r}=.497)$. The leisure helplessness had a positive correlation with physical activity satisfaction $(\mathrm{r}=.561)$, rest activity satisfaction $(\mathrm{r}=.578)$, and social activity satisfaction $(\mathrm{r}=.524)$. In other words, it was found that leisure lifestyle had a positive correlation with both leisure immersion and life satisfaction.

\subsection{Relationship between leisure and leisure immersion}

Multiple regression analysis was conducted in order to investigate the relationship between leisure lifestyle and leisure immersion of marine leisure sports enthusiasts.

\subsubsection{Relationship between leisure lifestyle and behavioral immersion}

Table 1: Relationship between leisure lifestyle and behavioral immersion

\begin{tabular}{|c|c|c|c|c|c|c|}
\hline & $\mathrm{B}$ & $\mathrm{SE}$ & $\mathrm{Beta}$ & $t$ & tolerance & VIF \\
\hline Constant & -.355 & .161 & & $-2.205^{*}$ & & \\
\hline Family-oriented & .600 & .043 & .633 & $13.972^{* * *}$ & .539 & 1.854 \\
\hline Sensory pursuit & .001 & .049 & .001 & .025 & .464 & 2.157 \\
\hline Relationship-oriented & -.017 & .040 & -.020 & -.413 & .481 & 2.078 \\
\hline Rational planning & .228 & .053 & .196 & $4.316^{* * *}$ & .535 & 1.869 \\
\hline Work-oriented & .189 & .046 & .205 & $4.120^{* * *}$ & .449 & 2.229 \\
\hline Leisure helplessness & .006 & .045 & .006 & .142 & .540 & 1.853 \\
\hline $\mathrm{R}^{2}=.796$, Corrected $\mathrm{R}^{2}=.790, \mathrm{~F}=119.809^{* * * *}$ \\
${ }^{*} \mathrm{p}<.05{ }^{* * *} \mathrm{p}<.001$
\end{tabular}

As shown in "Table 1", leisure lifestyle had a statistically significant effect on behavioral immersion ( $\mathrm{F}=119.809$, $\mathrm{p}<.001)$. The explanatory power of this variable was approximately $79.6 \%\left(\mathrm{R}^{2}=.796\right)$. After investigating the beta values as a relative influence of leisure lifestyle on behavioral immersion, a positive influence was shown in family-oriented $(\beta=.633, \mathrm{p}<.001)$, rational planning $(\beta=.196$, $\mathrm{p}<.001) \quad$ and work-oriented $(\beta=.205, \quad \mathrm{p}<.001)$. 
In other words, it was found that family-oriented, rational planning, and work-oriented had a positive influence on the behavioral immersion.

\subsubsection{Relationship between leisure lifestyle and Cognitive immersion}

Table 2: Relationship between leisure lifestyle and cognitive immersion physical activity satisfaction.

\subsubsection{Relationship between leisure lifestyle and rest activity satisfaction}

Table 4: Relationship between leisure lifestyle and rest activity satisfaction

\begin{tabular}{|c|c|c|c|c|c|c|c|c|c|c|c|c|c|}
\hline & & & & & \multirow[b]{2}{*}{-.609} & & \\
\hline & & & & & & & Constant & -.122 & .201 & & & & \\
\hline & & IIIT- & & & & & Family-oriented & .255 & .054 & .246 & $4.764^{* * *}$ & .539 & 1.854 \\
\hline & B & SE & Beta & $t$ & tolerance & $\mathrm{VIF}$ & Sensory pursuit & .124 & .062 & .112 & $2.004^{*}$ & .464 & 2.157 \\
\hline Constant & .325 & .158 & & $2.055^{*}$ & & & Relationship-oriented & .387 & .050 & .419 & $7.676^{* * *}$ & .481 & 2.078 \\
\hline Family-oriented & -.048 & .042 & -.053 & -1.131 & .539 & 1.854 & Rational planning & .045 & .066 & .036 & .699 & .535 & 1.869 \\
\hline Sensory pursuit & .587 & .049 & .615 & $12.080^{\text {*** }}$ & .464 & 2.157 & Work-oriented & .205 & .057 & .203 & $3.581^{* * * *}$ & .449 & 2.229 \\
\hline Relationship-oriented & .145 & .040 & .182 & $3.637^{* * * *}$ & .481 & 2.078 & Leisure helplessness & .042 & .056 & .039 & .751 & .540 & 1.853 \\
\hline Rational planning & .044 & .052 & .040 & .838 & .535 & 1.869 & $\mathrm{R}^{2}=$ & $36, \mathrm{Cor}$ & ected 1 & $=.727$ & $85.349^{*}$ & & \\
\hline Work-oriented & .088 & .045 & .102 & 1.964 & .449 & 2.229 & $\mathrm{p}<.001$ & & & & & & \\
\hline
\end{tabular}

\begin{tabular}{|c|c|c|c|c|c|c|}
\hline Leisure helplessness & .107 & .044 & .115 & $2.433^{*}$ & .540 & 1.853 \\
\hline
\end{tabular}
$\mathrm{R}^{2}=.779$, Corrected $\mathrm{R}^{2}=.772, \mathrm{~F}=108.275^{*}$

$\mathrm{p}<.05,{ }^{* * * *} \mathrm{p}<.001$

As shown in "Table 2", leisure lifestyle had a statistically significant effect on cognitive immersion( $\mathrm{F}=108.275$, $\mathrm{p}<.001)$

and the explanatory power of this variable was approximately $77.9 \%\left(\mathrm{R}^{2}=.779\right)$. When looking at the beta values as a relative influence of leisure lifestyle on cognitive immersion, a positive influence was shown in sensory $\operatorname{pursuit}(\beta=.615, \quad \mathrm{p}<.001), \quad$ relationship-oriented $(\beta=.182$, $\mathrm{p}<.001)$, and leisure helplessness $(\beta=.115, \mathrm{p}<.001)$. In other words, it was found that sensory pursuit, relationship-oriented, and leisure helplessness had a positive influence on the cognitive immersion.

\subsection{Relationship between leisure lifestyle and leisure immersion}

Multiple regression analysis was conducted in order to investigate the relationship between leisure lifestyle and life satisfaction of marine leisure sports participants.

\subsubsection{Relationship between leisure lifestyle and life satisfaction}

Table 3: Relationship between leisure lifestyle and physical activity satisfaction

\begin{tabular}{|c|c|c|c|c|c|c|}
\hline & $\mathrm{B}$ & $\mathrm{SE}$ & Beta & $t$ & $\begin{array}{c}\text { toleranc } \\
\mathrm{e}\end{array}$ & $\mathrm{VIF}$ \\
\hline Constant & -.267 & .190 & & -1.409 & & \\
\hline Family-oriented & .498 & .051 & .503 & $9.843^{* * *}$ & .539 & 1.854 \\
\hline Sensory pursuit & .012 & .058 & .012 & .211 & .464 & 2.157 \\
\hline Relationship-oriented & .147 & .048 & .167 & $3.092^{* *}$ & .481 & 2.078 \\
\hline Rational planning & .234 & .062 & .192 & $3.752^{* * *}$ & .535 & 1.869 \\
\hline Work-oriented & .136 & .054 & .141 & $2.520^{*}$ & .449 & 2.229 \\
\hline Leisure helplessness & .034 & .053 & .033 & .650 & .540 & 1.853 \\
\hline \multicolumn{7}{|c|}{$\mathrm{R}^{2}=.741$, Corrected $\mathrm{R}^{2}=.732, \mathrm{~F}=87.699^{* * *}$} \\
\hline
\end{tabular}

As shown in "Table 3", leisure lifestyle had a statistically significant effect on physical activity satisfaction $(\mathrm{F}=87.699$, $\mathrm{p}<.001$ ), and the explanatory power of this variable was approximately $74.1 \%\left(\mathrm{R}^{2}=.741\right)$. When looking at the beta values as a relative influence of leisure lifestyle on physical activity satisfaction, a positive influence was shown in family-oriented $(\beta=.503, \quad \mathrm{p}<.001), \quad$ relationship-oriented $(\beta=.167, \mathrm{p}<.01)$, rational planning $(\beta=.192, \mathrm{p}<.001)$, and work-oriented $(\beta=.141, p<.05)$. In other words, it was found that family-oriented, relationship-oriented, rational planning, and work-oriented had a positive influence on the
As shown in "Table 4", leisure lifestyle had a statistically significant effect on rest activity satisfaction ( $\mathrm{F}=85.349$, $\mathrm{p}<.001$ ), and the explanatory power of this variable was approximately $73.6 \%\left(\mathrm{R}^{2}=.736\right)$. When looking at the beta values as a relative influence of leisure lifestyle on rest activity satisfaction, a positive influence was shown in family-oriented $(\beta=.246, p<.001)$, sensory $\operatorname{pursuit}(\beta=.112$, $\mathrm{p}<.05), \quad$ relationship-oriented $(\beta=.419, \quad \mathrm{p}<.001), \quad$ and work-oriented $(\beta=.203, p<.001)$. In other words, it was observed that family-oriented, sensory pursuit, relationship-oriented, and work-oriented had a positive influence on the rest activity satisfaction.

\subsubsection{Relationship between leisure lifestyle and social activity satisfaction}

Table 5: Relationship between leisure lifestyle and social activity satisfaction

\begin{tabular}{|c|c|c|c|c|c|c|}
\hline & $\mathrm{B}$ & $\mathrm{SE}$ & Beta & $t$ & tolerance & VIF \\
\hline Constant & .476 & .282 & & 1.685 & & \\
\hline Family-oriented & .329 & .075 & .322 & $4.367^{* * *}$ & .539 & 1.854 \\
\hline Sensory pursuit & .032 & .087 & .029 & .368 & .464 & 2.157 \\
\hline Relationship-oriented & .016 & .071 & .018 & .226 & .481 & 2.078 \\
\hline Rational planning & .268 & .093 & .214 & $2.894^{* * *}$ & .535 & 1.869 \\
\hline Work-oriented & .074 & .080 & .075 & .923 & .449 & 2.229 \\
\hline Leisure helplessness & .192 & .079 & .179 & $2.432^{*}$ & .540 & 1.853 \\
\hline \multicolumn{7}{|c|}{$\mathrm{R}^{2}=.459$, Corrected $\mathrm{R}^{2}=.442, \mathrm{~F}=26.060^{* * *}$} \\
$\mathrm{p}$
\end{tabular}

As shown in "Table 5", leisure lifestyle had a statistically significant effect on social activity satisfaction $(\mathrm{F}=26.060$, $\mathrm{p}<.001$ ), and the explanatory power of this variable was approximately $45.9 \%\left(\mathrm{R}^{2}=.459\right)$. When looking at the beta values as a relative influence of leisure lifestyle on social activity satisfaction, a positive influence was shown in family-oriented $(\beta=.322, \mathrm{p}<.001)$, rational planning $(\beta=.214$, $\mathrm{p}<.01)$, and leisure helplessness $(\beta=.179, \mathrm{p}<.05)$. In other words, it was found that family-oriented, rational planning, and leisure helplessness had a positive influence on the social activity satisfaction.

\section{DISCUSSION}

This study investigated the relationship between leisure immersion and life satisfaction with reference to the leisure lifestyle of marine leisure sports enthusiasts. The discussion based on the results of this study is as follows.

The leisure lifestyle of marine leisure sports participants has a positive 
correlation with leisure immersion and life satisfaction. Based on these findings, among the sub-variables of leisure life style, family-oriented, rational planning, and work-oriented all had a positive influence on behavioral immersion, and the sensory pursuit, relationships-oriented, and leisure helplessness all had a positive influence on cognitive immersion.

In other words, among the leisure lifestyle of marine leisure sports participants, it was observed that participants having higher values in family-oriented, rational planning, and work-oriented had higher behavioral immersion. In this regard, Lee \& Kim (24) noted that the lifestyle of MTB contest participants had a significant influence on behavioral immersion, and even in a study targeting the soccer club members (25), there was a significant relationship between lifestyle and leisure immersion. Specifically, it had a positive influence on behavioral immersion. Considering these findings, the leisure lifestyle that is usually work-oriented, family-oriented during weekends and makes every plan reasonably can be seen as having a positive influence on behavioral immersion.

In addition, among the leisure lifestyle of marine leisure sports enthusiasts, it was observed that participants who had higher values for sensory pursuit, relationship-oriented, and leisure helplessness had higher cognitive immersion. In this regard, in a study targeting the fitness club users, Lee (26) noted that the lifestyle had a significant influence on the cognitive immersion. In a study targeting tennis club members (27), it was reported that lifestyle and leisure immersion had a significant relationship and especially had a positive influence on the cognitive immersion. Considering these findings, the leisure lifestyle of marine leisure sports enthusiasts, who are fashion-conscious and who value their relationships with people, had a positive influence on the cognitive immersion.

In this study, among the leisure lifestyle, family-oriented, relationship-oriented, rational planning, and work-oriented all had a positive influence on the physical activity satisfaction. Family-oriented, sensory pursuit, relationship-oriented, and work-oriented all had a positive influence on rest activity satisfaction. The family-oriented, rational planning, and leisure helplessness all had a positive influence on social activity satisfaction. In other words, this is a result indicating that the leisure lifestyle of marine leisure sports participants had a positive influence on life satisfaction. In this regard, an exploratory study claiming that lifestyle of college students participating in leisure activities affect the life satisfaction (28), and a study claiming that participation in health Yoga program increases the life satisfaction being contributed by degree of immersion (29), and a study claiming that life satisfaction is a variable that significantly affects the life dance participants (30), and especially, a study claiming that the participation in winter leisure sports had a positive influence on life satisfaction (22), all support the results of this study. Through such results, as the leisure lifestyle of marine leisure sports enthusiasts had a partial positive influence on leisure immersion and life satisfaction. By understanding the leisure lifestyle of marine leisure sports participants, that continuous research and measures that can increase leisure immersion and life satisfaction are needed.

\section{CONCLUSION}

The purpose of this study was to investigate the relationship between leisure immersion and life satisfaction for the leisure lifestyle of marine leisure sports participants. In order to do this, a questionnaire survey was conducted targeting 256 marine leisure sports participants in 2018. For the analysis of this survey, SPSS 12.0 statistical program. Frequency analysis, exploratory factor analysis, reliability test, correlation analysis, and multiple regression analysis were conducted using the program. Based on analysis of this results, the following conclusions were reached. First, the leisure lifestyle of marine leisure sports enthusiats had a positive correlation with leisure immersion and life satisfaction. Second, among the leisure lifestyle, family-oriented, rational planning, and work-oriented all had a positive influence on the behavioral immersion, and the sensory pursuit, relationship-oriented, and leisure helplessness all had a positive influence on cognitive immersion.

Third, among the leisure lifestyle, family-oriented, relationship-oriented, rational planning, and work-oriented all had a positive influence on the physical activity satisfaction, and family-oriented, sensory pursuit, relationship-oriented, and work-oriented all had a positive influence on rest activity satisfaction, and the family-oriented, rational planning, and leisure helplessness all had a positive influence on social activity satisfaction.

In conclusion, the leisure lifestyle of marine leisure sports enthusiasts had a positive correlation with leisure immersion and life satisfaction. It was observed that the leisure lifestyle had a partial influence on leisure immersion, and the behavioral immersion and cognitive immersion affecting the leisure lifestyle were incompatible with each other. In addition, the leisure lifestyles had a partial impact on life satisfaction, where among them, the leisure lifestyle of family-oriented, relationship-oriented, and work-oriented all had an influence on the life satisfaction.

\section{APPENDIX}

It is optional. Appendixes, if needed, appear before the acknowledgment.

\section{ACKNOWLEDGMENT}

It is optional. The preferred spelling of the word "acknowledgment" in American English is without an "e" after the "g." Use the singular heading even if you have many acknowledgments. Avoid expressions such as "One of us (S.B.A.) would like to thank ... ." Instead, write "F. A Author thanks " Sponsor and financial support acknowledgments are placed in 
the unnumbered footnote on the first page.

\section{REFERENCES}

1. M.G. Kang, W.S. Kim, "Residents' expectations, social trust and consciousness according to the Marina Development as the Marine Leisure Sports Facilities". Korean society for the sociology of sport. 26(3), 53-77, 2013.

2. B.H. Lee, S.S. Kim, "The Relationships between Satisfaction with Participation and the Repurchase Intention according to Lifestyle Characteristics of Sports Center Participants". Korea sport society. 11(1), 131-143, 2013.

3. K.S. Lee, "Study on the urban housing corresponding to the lifestyle". Master, Hanyang University, 2012.

4. S.S. Oh, J.S. Kim, W.S. Choi, "The Study of Constraints on the Level of Leisure Participation and Life Satisfaction". Korean Journal of Sports Science. 20(1), 285-295, 2011.

5. H.C. Joo, S.H. Kim, "The Relationship Among Leisure Life Style, Leisure Satisfaction and Life Satisfaction of College Students". Korea Society for Wellness. 8(4), 57-72, 2013.

6. J.Y. Lee, "The Relationships among Leisure Perception, Leisure-related Social Support and Health of Leisure Activity Participants". Journal of Korean Sociology of Sport. 11(1), 227-244, 1999.

7. Y.M. Chung, "A Study on Casual Relationships among Participation Motivation, Sports Commitment and Leisure Satisfaction". Korean Journal of Physical Education. 40(1), 749-760, 2001.

8. K.B. Kim, "Influence of perceived leisure constraint and leisure satisfaction on the leisure immersion of high school students". Master, Pusan National University, 2003.

9. M.J. Ji, "Analysis on Relationship among Leisure Constraint, Flow Experience, Lifestyle type". Journal of Sport and Leisure Studies. 30, 973-984, 2007.

10. Y.R. Kim, "Effects of Lifestyle on Leisure Flow and Satisfaction of University Students". Master, Dankook University, 2011

11. Y.J. Ko, "The Difference of participation Motives and Satisfaction of Sports participation of the aged According to the Types of Lifestyles". Journal of Korean Society of Sport Policy. 12, 1-13, 2008

12. S.H. Kim, "Influence of Life Satisfaction on the Sports Participation according to Life-style of University Students". Master, Kookmin University, 2006

13. S.N. Woo, "The Development Study of The Leisure Life Style Scale." Journal of Leisure Studies. 7(1), 1-26, 2009.

14. Y.M. Sohn, S.S. Oh, S.N. Woo, "The Study on the Criterion-related Validity of the Leisure Life Style Scale". Journal of leisure and recreation studies. 34(2), 111-124, 2010.

15. K.S. Lee, K.J. Kim, "The Influence of Participation Motivation and Life Styles on Leisure Satisfaction, Leisure Flow and Self-Esteem of College Student". Journal of leisure and recreation studies. 34(2), 59-70,2010 .

16. T.K. Scanlan, P.J. Carpenter, M. Lobel, "Simons JP, Keeler B, Schmidt GW. A model of sport commitment, paper present at the annual meeting of the north American society for the psychology of sport and physical activity". Houston, TX, 1990

17. B.W. Ahn, S.H. Hwang, "Relationship Between Leisure Competence, Flow, Leisure Satisfaction, and Self-Efficacy in Leisure Sports Participants". Journal of Leisure Studies. 9(3), 1-19, 2012.

18. Y.S. Yoon, "The effect of leisure flow experience of Paragliding participants on Leisure identity and Life satisfaction". Journal of leisure and recreation studies. 34(2), 195-204, 2010.

19. H.H. Kim, C.W. Lee, H.S. Jeon, "The relationship between serious Leisure and Leisure flow of Han river water Leisure participants. Journal of leisure and recreation studies". 35(4), 113-125, 2012.

20. M.G. Raghed, J.C. Beard, "Measuring leisure Satisfaction. Journal of Leisure Research". 1,576-587, 1980.

21. S.R. Ha, "The Relationships among Leisure Motivation, Leisure Attitude, and College Life Satisfaction in Korean College Students. Journal of leisure and recreation studies". 37(4), 15-32, 2013.

22. B.W. Jang, S.W. Lee, J.B. Kim, H.H. Lee, S.J. Oh, B.I. Yun, H.N. Yun, J.Y. Dong, T.Y. Jang, D.S. Han, "Analysis of Cause and Effect for Participants` Life Satisfaction in Winter Leisure Sports. Korean Society of Sport Psychology". 19(2), 215-231, 2008.

23. T.Y. Moon, "The Effects of the Type of Involvement in Marine Sport Tourism on Flow Experience and Life Satisfaction". Korea sport research. 17(2), 809-816, 2006

24. K. J. Lee, S.S. Kim, "The Relationship among Life Style, Absorption Experience and Life Satisfaction of MTB Tournament Participants. Korean Sport Society". 8(2), 253-262, 2010.

25. Y.T. Kim, S.H. Song, "The Relationship between Lifestyle Type, Sport Commitment and Leisure Identity according to Soccer Activity
Participations of Individual Character. Journal of Korean Society for the Study of Physical Education, 16(4), 99-117, 2011.

26. J.W. Lee, "The relationship between participation motivation, flow, affective Loyalty and customers ' behavioral intention of fitness club in university". Journal of leisure and recreation studies. 32(1), 25-36, 2008.

27. W.H. Lee, Y.S. Jung, S.B. Kong, W.K. Kim, "The Influence of Participation motivation and flow experience on Life satisfaction for tennis club members". Journal of leisure and recreation studies. 33(1), 17-27, 2009.

28. B.H. Kang, H.S. Kim, "The Causal Relationship Model among Life style, participation of Sport for all, and School Satisfaction of the Universities". Korean Journal of Physical Education. 39(4), 1001-1013, 2000.

29. T.Y. Moon, "The Effects of Leisure Flow Experience of Participants in Health Yoga Program on Leisure Satisfaction and Life Satisfaction". Journal of Sport and Leisure Studies. 30, 895-912, 2007.

30. H.S. Sin, S.I. Oh, "The Relationship of Participation Satisfaction, Leisure Flow and Life Satisfaction according to Participation in Life Dance". Journal of Sport and Leisure Studies. 30, 951-962, 2007.

\section{AUTHORS PROFILE}

Han, Kyung-Seok, Director of Hansmarine Research Institute, Korea.

Yang, Chun-Ho, Professor, Dept. of Leisure Marine Sports, Hanseo University, Korea, Chief of Library, Hanseo University, Kore 